УДК 543.641

\title{
КОЛИЧЕСТВЕННОЕ ОПРЕДЕЛЕНИЕ ДВУХ ГРУПП ТЕРПЕНОВЫХ СОЕДИНЕНИЙ МЕТОДОМ ХРОМАТО-МАСС-СПЕКТРОМЕТРИИ
}

\author{
(ㄱ) А.Н. Нарчуганов, А.А. Ерремов" \\ Сибирский фредеральный университет, пр. Свободный, 79, Красноярск, \\ 660041 (Россия), e-mail: aefremov@sfu-kras.ru.
}

В работе представлена методика анализа растительного сырья для количественного определения 10 монотерпенов и 20 сесквитерпенов методом ГХ-МС. Для количественного определения содержания монотерпенов в качестве стандартного образца предложено использовать $\alpha$-пинен, для определения сесквитерпенов - $\gamma$-кадинен. Представлены результаты анализа эфирных масел, полученных из древесной зелени хвойных растений Сибирского региона.

Ключевые слова: терпены, эфирное масло, количественное определение, хромато-масс-спектрометрия, пихта сибирская, сосна сибирская.

\section{введение}

При определении летучих биологически активных веществ, содержащихся в растительном сырье, первое место среди других аналитических методов занимает, безусловно, хромато-масс-спектрометрия. Этот метод является гибким и универсальным, а выпускаемые за рубежом и в последние годы в России газовые масс-спектрометры отличаются высокой надежностью и просты в эксплуатации. Хромато-массспектрометрия оказывается незаменимой при решении исследовательских задач: масс-спектры большинства летучих БАВ растительного сырья приведены в так называемых библиотеках масс-спектров, что позволяет проводить качественную идентификацию компонентов сложных смесей путем сопоставления экспериментальной и библиотечной информации. Для повышения надежности идентификации рекомендуется дополнительно проводить расчет линейных индексов удерживания. Сравнение экспериментального и библиотечного индексов удерживания дает дополнительную хроматографическую точку идентификации, сочетание которой с масс-спектрометрическими точками идентификации позволяет проводить определение качественного состава более надежно [1].

Для количественного хромато-масс-спектрометрического определения компонентов сложной смеси, как правило, используют метод внутренней нормировки. При этом суммарная площадь хроматографических писков принимается за 100\%, а содержание отдельных компонентов определяется в массовых процентах пропорционально их площади. Этот метод расчета едва ли можно назвать точным: отклик массспектрометра сильно зависит от строения определяемого вещества. Ошибка количественного определения может достигать $20 \%$ и более.

Более точным является метод внутреннего стандарта, который также часто используется в хроматомасс-спектрометрических методиках. Однако он не применим при анализе сложных смесей БАВ, выделяемых из растительного сырья. Это связано с отсутствием стандартных образцов на большинство подобных соединений. В данной работе предложен подход, предполагающий количественное определение двух групп терпеновых соединений, с использованием только одного из членов группы в качестве внутреннего

Нарчуганов Антон Николаевич - аспирант кафедры аналитической и органической химии Института цветных металлов и материаловедения, тел.: (391) 246-99-41, e-mail: anarchuganov@ sfu-kras.ru Ефремов Александр Алексеевич - заведующий лабораторией хроматографических методов анализа центра коллективного пользования, доктор химических наук, профессор, e-mail: AEfremov@sfu-kras.ru стандарта для определения остальных. Членами группы являются изомерные терпены, схожие по механизму фрагментации при масс-спектрометрическом детектировании. Было сделано предположение, что отклик масс-спектрометра на эти соединения является одинаковым с некоторой погрешностью, не превышающей случайную погрешность метода.

\footnotetext{
* Автор, с которым следует вести переписку.
} 


\section{Экспериментальная часть}

Анализировали образцы эфирного масла и гексановые экстракты древесной зелени хвойных растений, богатые моно- и сесквитерпеноидами. Анализируемый образец эфирного масла объемом 1 мкл помещали в виалу, добавляли 600 мкл $н$-гексана, тщательно перемешивали и помещали в автосэмплер. Объем вводимой пробы - 1 мкл. Растворы, полученные после перегонки гексановых экстрактов, как правило, отличались невысокими концентрациями терпеноидов и анализировались без дополнительного разбавления. Параметры хроматографа устанавливали на основе рекомендаций, приведенных в [2]: температура испарителя $-250{ }^{\circ} \mathrm{C}$, режим ввода - с делением потока, коэффициент деления - 19 : 1 . Анализ вели на кварцевой капиллярной колонке HР-5ms длиной 30 м и внутренним диаметром - 0,25 мм, неподвижной фазой служил 5\%-дифенил-95\%-диметилсилоксан, толщина пленки неподвижной фазы 0,25 мкм. Газ-носитель - гелий с постоянной скоростью потока 1 мл/мин. Использовали следующий режим программирования температуры: начальная температура колонки составляла $50{ }^{\circ} \mathrm{C}$ (удерживается 2 мин), затем градиентный подъем температуры $4 \%$ мин до $180{ }^{\circ} \mathrm{C}$, затем градиентный подъем со скоростью $25^{\circ}$ мин до $280{ }^{\circ} \mathrm{C}$ (удерживается 5 мин). Общее время анализа составляло 43,5 мин. Параметры масс-спектрометра: задержка растворителя (время от начала анализа до подачи тока на источник ионов) составляла 4 мин, ионизация электронная с энергией электронов 70 эВ. Температура интерфейса (хроматограф - масс-спектрометр) составляла $280{ }^{\circ} \mathrm{C}$, температура источника ионов $-230^{\circ} \mathrm{C}$, температура квадруполя $-150{ }^{\circ} \mathrm{C}$. Масс-спектрометр работал в режиме регистрации полного ионного тока.

\section{Обсуждение результатов}

Путем анализа масс-спектров было выявлено две группы терпенов: 10 монотерпенов с основным ионом $\mathrm{m} / \mathrm{z}=93$ в масс-спектре и 20 сесквитерпенов с основным ионом $\mathrm{m} / \mathrm{z}=161$. Для проверки гипотезы об одинаковом отклике масс-спектрометра на изомерные соединения и, соответственно, подтверждения однородности представленных групп провели анализ одних и тех же проб на хромато-масс-спектрометре и на газовом хроматографе с пламенно-ионизационным детектором. Известно, что отклик пламенноионизационного детектора (ПИД) незначительно изменяется для соединений одного класса. Установлено, что отклик масс-спектрометрического детектора коррелирует с откликом ПИД для всех моно- и сесквитерпенов, входящих в исследуемые группы, это подтверждает рассматриваемую гипотезу.

Хроматограммы эфирного масла сосны сибирской представлены на рисунках 1 и 2 . Качественную идентификацию проводили путем сопоставления масс-спектров и индексов удерживания.

Рабочие растворы (7 уровней концентрации) для построения градуировочного графика готовили из стандартных образцов терпенов методом последовательного разбавления. В качестве растворителя использовался гексан. Каждый рабочий раствор содержал стандарт для определения монотерпенов $(\alpha-п и н е н)$ и сесквитерпенов ( $\gamma$-кадинен). Каждый раствор анализировался в 6 параллелях, относительное стандартное отклонение не превышало 3\%. Уравнения калибровочных кривых и коэффициенты регрессии для соответствующих диапазонов определяемых содержаний приведены в таблице 1 .

Таким образом, приемлемый уровень коэффициента регрессии для обоих аналитов находится в двух диапазонах концентраций: 5-200 и 5-2000 мг/л. Тем не менее использовали меньший из двух диапазонов, поскольку было установлено, что высокие концентрации аналитов вызывают перегрузку колонки.

В качестве образцов для оценки прецизионности в условиях повторяемости использовали эфирное масло пихты сибирской и сосны сибирской, а также гексановый экстракт сосны сибирской. Анализ проводили в 10 параллелях, в одинаковых условиях и практически одновременно. Количество $\alpha$-пинена определяли методом градуировочного графика, количество остальных монотерпенов - методом внутреннего стандарта по $\alpha$-пинену, коэффициент пересчета 1,00 . Количество $\gamma$-кадинена определяли методом градуировочного графика, количество остальных сесквитерпенов - методом внутреннего стандарта по $\gamma$-кадинену, коэффициент пересчета 1,00. Установлено, что погрешность определения, выраженная в относительных единицах, не превышала 4\%. Значение предела обнаружения для обоих аналитов было определено графически по зависимости соотношения сигнал - шум от концентрации, предел обнаружения соответствовал соотношению сигнал - шум $3: 1$. Предел обнаружения для $\alpha$-пинена составил 0,3 мг/л, для $\gamma$-кадинена - 0,2 мг/л.

Для проверки правильности методики был использован метод «введено - найдено». В пробы эфирных масел (с разбавлением) и экстрактов добавлено определенное количество смеси стандартов, содержащей $\alpha$-пинен и $\gamma$-кадинен. Проанализированы исходные образцы и образцы с добавкой. Результаты представлены в таблице 2 .

Представленная методика апробирована на образцах эфирного масла, полученного из древесной зелени пихты сибирской и сосны сибирской. Результаты отражены в таблице 3. 


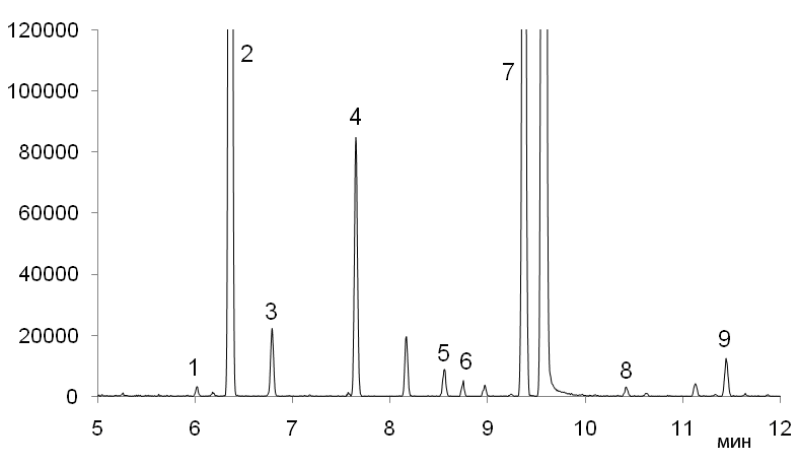

Рис. 1. Хроматограмма образца эфирного масла сосны сибирской, область монотерпенов:

1 - трициклен, 2 - $\alpha$-пинен, 3 - камфен,

4 - $\beta$-пинен, 5 - $\alpha$-фелландрен, 6 - 3-карен,

7 - $\beta$-фелландрен

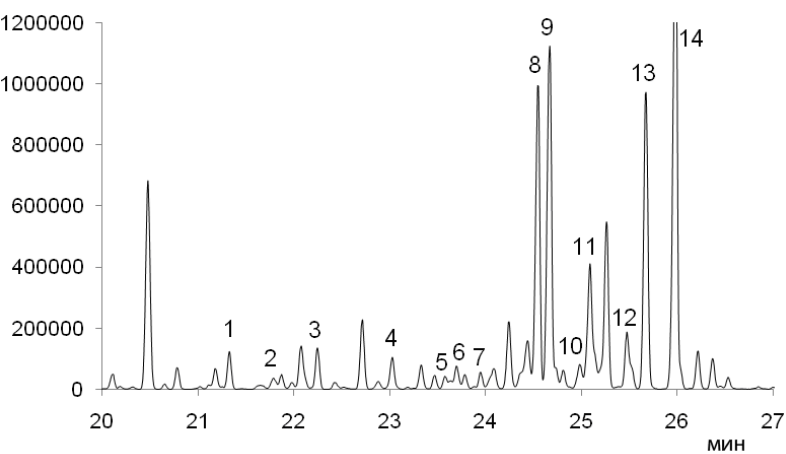

Рис. 2. Хроматограмма образца эфирного масла сосны сибирской, область сесквитерпенов:

1 - $\alpha$-копаен, 2 - $\beta$-кубебен, 3 - $\beta$-фунебрен,

4 - $\beta$-копаен, 5 - изис-мурола-3,5-диен,

6 - транс-мурола-3,5-диен, 7 - цис-мурола-4(14),5диен, 8 - транс-кадина-1(6),4-диен,

9 - гермакрен Д, 10 - бициклосесквифелландрен, 11 - $\gamma$-аморфен, $12-\delta$-аморфен, $13-\gamma$-кадинен, $14-\delta$-кадинен

Таблица 1. Результаты калибровки по $\alpha$-пинену и $\gamma$-кадинену

\begin{tabular}{c|c|c|c}
\hline Аналит & $\begin{array}{c}\text { Диапазон линейности } \\
\text { градуировочного графика, мг/л }\end{array}$ & Уравнение калибровочной кривой & $\begin{array}{c}\text { Коэффициент } \\
\text { регрессии }\end{array}$ \\
\hline \multirow{5}{*}{$\alpha$-пинен } & $5-5000$ & $\mathrm{~S}=1,09 \cdot 10^{5} \mathrm{C}+7 \cdot 10^{6}$ & 0,9970 \\
& $5-2000$ & $\mathrm{~S}=1,23 \cdot 10^{5} \mathrm{C}+2 \cdot 10^{6}$ & 0,9993 \\
& $5-500$ & $\mathrm{~S}=1,35 \cdot 10^{5} \mathrm{C}+5,06 \cdot 10^{5}$ & 0,9979 \\
\hline \multirow{3}{*}{$\gamma$-кадинен } & $5-200$ & $\mathrm{~S}=1,51 \cdot 10^{5} \mathrm{C}-3,18 \cdot 10^{5}$ & 0,9993 \\
& $5-5000$ & $\mathrm{~S}=1,84 \cdot 10^{5} \mathrm{C}+2 \cdot 10^{7}$ & 0,9843 \\
& $5-2000$ & $\mathrm{~S}=2,41 \cdot 10^{5} \mathrm{C}-1 \cdot 10^{6}$ & 0,9996 \\
\hline
\end{tabular}

Таблица 2. Результаты анализа проб эфирного масла

\begin{tabular}{c|c|c|c|c}
\hline \multicolumn{1}{c|}{ Проба } & Аналит & $\begin{array}{c}\text { Содержание аналита } \\
\text { в исходной пробе, мг/л }\end{array}$ & $\begin{array}{c}\text { Введено } \\
\text { аналита, мг/л }\end{array}$ & $\begin{array}{c}\text { Найдено } \\
\text { аналита, мг/л }\end{array}$ \\
\hline Эфирное масло пихты сибирской & $\alpha$-пинен & $152,6 \pm 1,6$ & 50 & $48,2 \pm 1,6$ \\
Эфирное масло сосны сибирской & $\gamma$-кадинен & $14,2 \pm 1,3$ & 10 & $9,8 \pm 1,4$ \\
\multirow{2}{*}{ Экстракт сосны сибирской } & $\alpha$-пинен & $24,3 \pm 1,5$ & 10 & $9,8 \pm 1,5$ \\
\multirow{2}{*}{ Экстракт сосны обыкновенной } & $\gamma$-кадинен & $9,4 \pm 1,4$ & 10 & $9,6 \pm 1,4$ \\
& $\alpha$-пинен & $19,8 \pm 1,4$ & 10 & $10,2 \pm 1,5$ \\
\hline
\end{tabular}

Таблица 3. Содержание некоторых моно- и сесквитерпенов в эфирных маслах пихты сибирской и сосны сибирской

\begin{tabular}{|c|c|c|c|c|}
\hline \multirow{2}{*}{ № } & \multirow{2}{*}{ Компонент } & \multirow{2}{*}{$t_{r}$ мин } & \multicolumn{2}{|c|}{ Содержание в эфирных маслах (г/л): } \\
\hline & & & пихты сибирской & сосны сибирской \\
\hline 1 & 2 & 3 & 4 & 5 \\
\hline 1 & Трициклен & 6,02 & 20,5 & 1,4 \\
\hline 2 & $\alpha$-пинен & 6,40 & 92,9 & 392,6 \\
\hline 3 & Камфен & 6,87 & 197,1 & 9,6 \\
\hline 4 & Сабинен & 7,53 & $<0,2$ & 0,2 \\
\hline 5 & $\beta$-пинен & 7,65 & 16,4 & 36,9 \\
\hline 6 & $\alpha$-фелландрен & 8,56 & 2,0 & 4,1 \\
\hline 7 & 3-карен & 8,77 & 98,1 & 1,9 \\
\hline 8 & $\beta$-фелландрен & 9,42 & 86,8 & 181,0 \\
\hline 9 & $\gamma$-терпинен & 10,42 & 1,7 & 1,4 \\
\hline
\end{tabular}


Окончание таблищьы 3

\begin{tabular}{|c|c|c|c|c|}
\hline 1 & 2 & 3 & 4 & 5 \\
\hline 10 & Терпинолен & 11,45 & 11,6 & 6,2 \\
\hline 11 & $\alpha$-кубебен & 20,50 & $<0,2$ & $<0,2$ \\
\hline 12 & $\alpha$-копаен & 21,34 & $<0,2$ & 1,2 \\
\hline 13 & $\beta$-кубебен & 21,82 & $<0,2$ & 0,3 \\
\hline 14 & $\beta$-фунебрен & 22,30 & 0,9 & 1,4 \\
\hline 15 & $\beta$-кедрен & 22,50 & $<0,2$ & $<0,2$ \\
\hline 16 & $\beta$-копаен & 23,04 & $<0,2$ & 1,0 \\
\hline 17 & $\beta$-гурьюнен & 23,15 & $<0,2$ & $<0,2$ \\
\hline 18 & Изогермакрен Д & 23,51 & $<0,2$ & $<0,2$ \\
\hline 19 & цис-муурола-3,5-диен & 23,59 & $<0,2$ & 0,3 \\
\hline 20 & транс-муурола-3,5-диен & 23,71 & $<0,2$ & 0,5 \\
\hline 21 & ųис-муурола-4(14),5-диен & 24,10 & $<0,2$ & $<0,2$ \\
\hline 22 & $\beta$-неокловен & 24,30 & $<0,2$ & $<0,2$ \\
\hline 23 & транс-кадина-1(6),4-диен & 24,46 & $<0,2$ & 0,9 \\
\hline 24 & $\gamma$-мууролен & 24,56 & $<0,2$ & 9,5 \\
\hline 25 & Гермакрен Д & 24,69 & $<0,2$ & 11,1 \\
\hline 26 & Бициклосесквифелландрен & 25,03 & 0,2 & 0,7 \\
\hline 27 & $\gamma$-аморфен & 25,10 & 0,3 & 3,9 \\
\hline 28 & $\delta$-аморфен & 25,49 & $<0,2$ & 2,4 \\
\hline 29 & $\gamma$-кадинен & 25,69 & $<0,2$ & 10,0 \\
\hline 30 & $\delta$-кадинен & 26,05 & 0,2 & 17,6 \\
\hline
\end{tabular}

\section{Bbыводы}

1. Предложена эффективная методика количественного определения групп моно- и сесквитерпенов, предполагающая использование одного из веществ определяемой группы в качестве внутреннего стандарта для определения остальных, с коэффициентом пересчета, принимаемым равным единице.

2. Определены метрологические характеристики представленной методики, проведена апробация на образцах эфирного масла, полученного из древесной зелени хвойных растений Сибирского региона.

\section{Список литературы}

1. Журкович И.К., Мильман Б.Л. Общая характеристика современных методик анализа. Пример масс-спектрометрии и хромато-масс-спектрометрии // Журнал аналитической химии. 2009. Т. 64, №10. С. 1012-1021.

2. Ткачев А.В. Исследование летучих веществ растений. Новосибирск, 2008. 969 с.

Поступило в редакиию 26 января 2013 г.

После переработки 13 марта 2013 г.

Narchuganov A.N., Efremov A.A. ${ }^{*}$ QUANTITATIVE DETERMINATION OF TWO GROUPS OF TERPENS BY GC-MS METHOD

Siberian Federal University, st. Svobodnyi, 79, Krasnoyarsk, 660041 (Russia), e-mail: AEfremov@sfu-kras.ru

In this work was presented a method of analysis of plant materials for the quantitative determination of 10 monoterpens and 20 sesquiterpens using GC-MS. For determination of quantity of monoterpens was used the $\alpha$-pinene as an analytical standard, and for determination of sesquiterpens - the $\gamma$-cadinene. Also, in this work was shown results of the analysis of the essential oils, made from green wood of coniferous plants of Siberia.

Keywords: terpens, essential oil, quantitative determination, GC-MS, Juniperus Sibirica, Pinus Sibirica.

\section{References}

1. Zhurkovich I.K., Mil'man B.L. Zhurnal analiticheskoi khimii, 2009, vol. 64, no. 10, pp. 1012-1021. (in Russ.).

2. Tkachev A.V. Issledovanie letuchikh veshchestv rastenii. [The study of plant volatiles]. Novosibirsk, 2008,969 p. (in Russ.).

\footnotetext{
* Corresponding author.
} 